\title{
From Social Research to Education and Training - Campaigns to Raising Public Awareness of Hazards
}

\author{
Barbara Szykuła - Piec (Corresponding author) \\ The Main School of Fire Service \\ Slowackiego st. 52/54 01-629 Warsaw, Poland \\ E-mail: bpiec@sgsp.edu.pl \\ Izabella Grabowska - Lepczak \\ The Main School of Fire Service \\ Slowackiego st. 52/54 01-629 Warsaw, Poland \\ E-mail: igrabowska@sgsp.edu.pl \\ Monika Wojakowska \\ The Main School of Fire Service \\ Slowackiego st. 52/54 01-629 Warsaw, Poland \\ E-mail:mwojakowska@sgsp.edu.pl
}

Received: January 23, 2020

doi:10.5296/jet.v7i2.16323

\author{
Accepted: April 15, $2020 \quad$ Published: August 20, 2020 \\ URL: http://dx.doi.org/10.5296/jet.v7i2.16323
}

\begin{abstract}
The education of society regarding safety is in fact the cheapest, smartest and most effective form of preventing danger. It constitutes a fundamental way of building the population's safety. It also has a great influence upon the attitudes, values, knowledge and skills required for proper behaviour in case of danger.

The article describes the education process consisting in the transfer of knowledge and teaching skills in order to take specific actions, as well as forms and tools to raise the level of social awareness, especially in terms of perceiving actions, and a list of references showing the flow of social research, its purpose, and the tools used. Most of the elements, however, are shown in the list of possibilities to use tools on a very large scale, in the form of social campaigns. An example is given of a practical approach to all departments and goals for raising the level of social opinion in Transcarpathia and of hazadrs occurring in that area and ways to counteract them.
\end{abstract}

Keywords: Education for Safety, Training, Education, Environment, Social Campaign, Social Research, Raising Awareness 


\section{Introduction}

The safety environment is very dynamic. The scale of hazards and challenges that local communities have to face is very large. That is why there is a need to shape a culture of safety by building civic engagement and responsibility in the context of individual and collective safety. Therefore information channels suitable for the group of recipients should be selected, which will enable the dissemination of knowledge about the essence of the problem in the social space, along with proposals for preventive solutions in this respect. It has been stated that the best form of promoting a culture of safety is a social campaign.

Before we describe one of the methods to fill gaps in the awareness of local communities in relation to the threats in their homes, it is worth considering the knowledge necessary to achieve the intended results. This knowledge can be obtained in the course of scientific research, whose strong influence has been noted in many areas of social life.

The article will describe the role of social sciences in shaping human awareness. Methods for shaping public awareness using social campaigns as smart education will be presented.

As justification, a description will be given of activities carried out in the Transcarpathian region of Ukraine, where the risk of disasters and other local threats is very high.

\section{The Role of Social Research in Identifying Gaps in Awareness}

\subsection{What is the Social Impact of Research?}

Today, we are dealing with a renaissance of social research, the results of which are used on many levels of life. It is worth noting that society can profit from scientific research mainly when the results are transformed into ready-made, universal practical products, but also into services (Bornmann, 2013) that can be used. The impact of research with tangible results in the form of implemented patents or new technological solutions is obvious, but the benefits of social research are more difficult to assess (Salter \& Martin, 2001). Defining the impact of research on society, we direct our considerations, among others, towards social benefits (van der Meulen \& Rip, 2000) and the usefulness (Department of Education Science and Training, 2005) of a kind of knowledge transfer (van Vught \& Ziegele, 2011) which directly translates into development in four dimensions: social, cultural, environmental and economic.

So the social dimension concerns the contribution of research to the multiplication of social capital, understood as a peculiar resource of lasting social commitments and ties, activated and used collectively (Bourdieu, 1979), an important element of the social structure that is the skeleton for undertaking actions (Coleman, 1990) and achieving goals, being a common good, strongly and positively correlated with the efficiency of society (Putnam, 2008). In this dimension, research makes it possible to identify the social needs articulated by societies.

In the cultural dimension, an important role is played by historic research and, based on past experience, the resulting possibility of increasing contemporary civilization resources, while taking into account relationships with other societies and cultures (Bornmann, 2012). This dimension includes research into the impact of norms, principles and structures on sustainable social development. 
Impact in the environmental dimension can be measured by the benefits of research for the natural environment, converted into measures to minimise waste and pollution. The presented research results promote activities related to opposing the devastation of nature, maximising the protection of natural reserves, caring for biodiversity or protecting and defending endangered species, living beings that are an immanent element of life on Earth.

The impact of research in the economic dimension brings benefits that increase effective and economic capital by multiplying skill bases and improving performance (Donovan, 2008).

All four dimensions overlap, creating a worked out space for creating reality. In connection with this, an important result of social research may be a change of attitudes, and thus behaviours, to ones that, according to selected theories of social sciences (Szykuła-Piec, 2018) (including theories of group solidarity, social resilience or a culture of trust as paradigms constituting the starting point for further social research), are desirable. It should be remembered that changes are introduced in the emotional, cognitive and behavioural areas to be able to talk about the success of the ongoing process of changing attitudes. Returning to the question of how this influence of research on society can be used, it is necessary to specify the purpose of research. Generally speaking, it is defined as a specific identification of the complexity of social life, gathering information about various social groups forming a given community and diagnosing needs. Then it becomes possible to prepare a transfer of knowledge to facilitate the proper action.

\subsection{Main Goals of Social Research}

Thus, in the course of the literature review (Ragin \& Amoroso, 1994) and our own considerations, it was assumed that the main goals of social research include identifying general patterns and principles of relations in society while discovering diversity, testing existing theories and improving and creating new ones, making predictions, and using acquired knowledge for practical application. With the growing knowledge of general patterns anchored in given communities, including behaviours, relationships, norms, values, existing relationships, etc., the general scientific knowledge about society increases, which translates directly into the possibility of creating universal theories as a basis for further analysis. The goal of defining a general pattern rather than knowing a single situation is an added value, because then we are dealing with a more general knowledge of things and not a detailed understanding of a one-off situation that does not offer universal knowledge that can be more widely used (Ragin \& Amoroso, 1994). However, it should be noted that there are situations where knowledge of specific, sometimes unusual, situations and events seems to be more valuable. These include processes of understanding social life, which should have their origin in the analysis of: historical events, individual experiences of the studied social groups, communities or individuals. The unique image of the research subject extracted during the investigation has a strong influence on how it is shaped today. In addition, it is possible to explore, understand and appreciate social diversity.

However, this general knowledge allows for the formulation of paradigms as theoretical initial matrices as well as for updating and extending existing theories by testing them by putting research hypotheses in real conditions. Collecting social data during the research 
process enables prediction, using accumulated scientific knowledge to predict upcoming events and phenomena. Knowing what to expect or being able to predict future development, such as potential disturbances, new requirements or limitations, new possibilities or changing operating conditions, is a value constituting one of the conditions for the ability of flexible operation, and resilience (Hollnagel, 2015). This strongly unitary goal implies the use of acquired knowledge in the form of social research results and provides decision-makers, and those who want to make use of the results obtained, with appropriate guidelines for policy making, the educational content provided, prevention, improvement of the quality of life, minimisation of threats and their potential effects, mitigation or conflict resolution in the social sphere, etc. The transfer of knowledge takes place on many levels with the participation of numerous actors who are carriers but also creators of social life, and is activated in stimulating new educational and training solutions, identifying gaps in consciousness, as well as in generating information on social needs in order to adapt social activity to existing conditions. In pursuing this unitary research goal, we suggest using the material collected in the course of the review of available reports (Note 1), the results of side tests (Note 2), and a focus group.

\subsection{The Focus Group Interview to Make it Easier to Identify Gaps in Awareness about Hazards}

The focus group interview (FGI) is a popular method of qualitative research and, as a discussion led by a moderator in a group of intentionally selected people (not from a statistically representative sample of a broader population), is an important tool from the point of view of the assumptions of research to gain an in - depth understanding of social issues. The discussion was focused on a specific topic related to awareness of hazards selected by participants who had filled out a questionnaire beforehand, because the FGI method is rarely used as a stand - alone technique. In this case, 12 teachers from different parts of the studied region participated. The advantage of focus group interviews is the short time it takes to obtain information, which gives the opportunity to observe the dynamics of respondents' attitudes and the interactions occurring between them. One type of focus group discussion involves creative groups - focused on carrying out creative tasks or solving a problem. The research used techniques aimed at stimulating creativity and achieving synergies of collaboration between the study participants, most often based on extensive heuristics, aiming to draw from the complex personal experiences, beliefs, perceptions and attitudes of the participants through a moderated interaction. As has already been said here, the main stage of the study is a group discussion by respondents selected for having specific features that are important from the point of view of the objectives of the study. In our case, the respondents were representatives of the teachers' professional group as education leaders and having a well-defined impact on society, with particular emphasis on children. The meeting was attended by teachers from Solotvyno schools and who represented various ethnic groups living in this area. One of the tools used during the focus group was the Disney method (Mulder, 2012), which helps to create, organise and implement ideas and solutions from different perspectives as the background for interviews. According to the Disney method, the most important starting point regarding the new solutions is to look at something from different perspectives and include all these ideas in the final conclusion. The main 
objective of the focus group was to identify the needs and level of public awareness about local hazards.

The teachers' answers indicate a big social awareness of problems with waste. Also the risk associated with landslides at closed salt mines additionally poses a great hazard for the local community, especially for children at play. These problems, in their opinion, are the biggest. They consistently agree that the main problem is the lack of system solutions - at each level. Teachers see the problem, and also have ideas for creative solutions, but the awareness of organisational and functional limitations is overwhelming. As a result of the group work analysis, the real difficulties and limitations in the system approach have been defined, including:

- the lack of city monitoring,

- the absence of consequences in penalising people for littering the environment,

- no containers for sorting waste,

- lack of education of children and youths (but also adults) about the value of caring for ecological cleanliness and safety attitudes.

But a priority for this research were difficulties and limitations in the cultural/mental field. As a result of the group work analysis, the real difficulties and limitations were defined:

- a deeper malaise among the people,

- indifference of society in the face of the lack of reaction from the authorities,

- low level of safety culture,

- no responsibility for the common good,

- lack of education of children and youths (but also adults) about the value of caring for ecological cleanliness.

In view of the gaps identified, the following recovery program is recommended:

- To organise information campaigns aimed at sensitising society to local problems,

- Continuous education on school safety, addressed to children and adolescents,

- Local initiatives undertaken in cooperation with local decision-makers.

The safety environment is very dynamic for the whole Transcarpathia region and in particular Solotvyno. The scale of hazards and challenges that local communities must face is very large. Therefore there is a need to establish a safety culture by building commitment and civil society's responsibility in the context of both individual and collective safety. The risk of disasters and other local hazards is very high for the Transcarpathian region. That is why information channels suitable for the group of recipients should be selected and defined persuasively, because the objective is not only to provide information but, above all, to change behaviours and attitudes - to socially desirable behaviours and attitudes. 
3. Social Campaigns as One of the Methods of Raising Awareness

\subsection{Types and Forms of Social Campaigns}

The modern world is so constructed that social campaigns are playing an increasingly important role in raising public awareness, but often overlook social problems.

The social campaign is an extremely important and valuable tool for social communication. This type of message is not aimed at increasing the sales of a product or making a profit, as in a commercial advertisement. Social campaigns promote ideas and new solutions in the area of preventive activities for safety.

According to Maison and Wasilewski, a social campaign is a kind of social communication, which is about promoting socially appropriate and valuable patterns of behaviour, attitudes and new values, or drawing the public's attention to important, often difficult and unresolved problems. "This is a statement that we can define as persuasive, because its objective is not only to provide the information, but also, and perhaps, to change behaviours and attitudes - to socially desirable behaviours and attitudes" (Maison \& Wasilewski, 2002).

A practical dimension and the first step in preparing a social campaign is for the research group to visit the region where the research process will be carried out. Meetings with groups of main recipients allow to know the main needs and threats perceived by representatives of the local community.

Meanwhile, according to Dobek-Ostrowskiej, "A communication campaign is a set of organizational and communication actions undertaken by public institutions, private companies, organisations, etc.; planned earlier, comprehensive and related to each other; possessing a specific, clearly defined objective, that is, creating desirable attitudes and behaviours in a relatively large number of people; addressed to a wide audience; realised within a specific time frame (from the inauguration to the end of the campaign); professionally managed and professionally carried out by professional communicators" (Dobek-Ostrowska, 2007).

One form of communication campaign is social campaigns. Their most important functions are:

- information function - providing recipients with information about threats or social actions, making them aware of the problem;

- a reminding function - raising a topic that was previously discussed;

- persuasive/convincing function - convincing recipients of the given ideas and behaviours (Kwiatkowska, 2003).

During the visit to Solotvyno, creative training was methodically organised as part of the workshops. The main goal was to show the importance of the ability to define yourself and your needs. Then, the group was allowed to make a cause-and-effect analysis of the selected local threat for Solotvyno. According to the proposed method, representatives of the local Solotvyno community (both ordinary citizens and local authorities) analysed the causes of hazards, their consequences and negative effects on various levels (including, for example, economic, social and environmental). However, the most valuable effect of the works was to create a concept of improvement and recommendations for changes towards system solutions. The first meeting with citizens of Solotvyno resulted in the statement that the most important element is the action plan, and the ability to create a future perspective. Such conclusions 
from the participants were really pleasing and justified the correctness of the research group's direction.

Information campaigns can be treated as one of a number of ways to solve social problems. They are a reaction by society to existing or newly emerging social problems, which can be solved not only through communication but also at the same time by legal, technical and economic means.

Table 1. Multicriteria classification of social campaigns

\begin{tabular}{|c|c|c|}
\hline No. & $\begin{array}{l}\text { Division } \\
\text { criterion }\end{array}$ & Characteristics \\
\hline 1. & $\begin{array}{l}\text { The } \\
\text { territorial } \\
\text { range }\end{array}$ & $\begin{array}{l}\text { - global campaigns - international (global or continental). Such campaigns are most } \\
\text { often implemented by international organisations such as the UN, UNESCO; } \\
\text { - national campaigns - covering the territory of one country. Communication } \\
\text { campaigns are undertaken at the initiative of public authorities; } \\
\text { - regional and local campaigns - addressed to recipients living in the region, } \\
\text { province, commune or city. }\end{array}$ \\
\hline 2. & Target group & $\begin{array}{l}\text { - general campaigns - addressed to the whole of society; } \\
\text { - dedicated campaigns - addressed to a specific audience, for example, to a selected } \\
\text { narrower group of recipients, to specific layers or segments of society depending on } \\
\text { age, gender, place of residence, tastes and needs. }\end{array}$ \\
\hline 3. & Objective & $\begin{array}{l}\text { - campaigns influencing behaviour - this may be soliciting and, consequently, } \\
\text { triggering specific pro-social behaviour; } \\
\text { - campaigns adopting the form of social communication - consist in making the } \\
\text { recipients aware and sensitised to the existing social problems or promoting values } \\
\text { and socially desirable norms, patterns, behaviours and beliefs; } \\
\text { - integration campaigns (for example: "Disabled people - a normal matter"); } \\
\text { - intervention campaigns (for example, "Stop violence") } \\
\text { - campaigns combating pathologies (for example: "Drugs: you take-lose); } \\
\text { - prevention campaigns (for example, "Young drivers"). }\end{array}$ \\
\hline 4. & Character & $\begin{array}{l}\text { - campaigns changing behavioural intentions; } \\
\text { - educational campaigns, providing information and raising the level of knowledge } \\
\text { about the problem; } \\
\text { - campaigns promoting financial support; } \\
\text { - campaigns promoting any events; } \\
\text { - regional or city campaigns. }\end{array}$ \\
\hline 5. & Time & $\begin{array}{l}\text { - cyclical campaigns; } \\
\text { - one-off campaigns. }\end{array}$ \\
\hline 6. & $\begin{array}{l}\text { Ordering } \\
\text { institution }\end{array}$ & $\begin{array}{l}\text { - campaigns planned and implemented from above (e.g. in the case of institutions } \\
\text { with adequate financial resources); } \\
\text { - unplanned and bottom-up campaigns (in the case of, for example, social } \\
\text { movements, civic initiatives). }\end{array}$ \\
\hline
\end{tabular}

Source: M. Wojakowska, own elaboration based on the literature of the subject. 
Social campaigns can also be defined through the prism of social change, in which the actions of a given group of people are focused on convincing other people to modify, accept or cease specific practices, behaviours, beliefs or values. For the needs of the realised project, it was assumed that this social campaign will be informative, persuasive and convincing. The informational dimension of the campaign will be provided by messages in the local press, leaflets distributed during themed events and newsletters sent by local offices, as well as in the handbook and during workshops addressed to local authorities.

Meanwhile, the convincing aspect will be included in direct meetings with the local community during the events in the workshop classes with children and youths in schools, community centres or municipal libraries using educational games and other activities.

Social campaigns can be classified according to several criteria, as presented in the following table (Table 2).

\subsection{Methodology of Conducting the Campaign}

Table 2. Stages of designing a social campaign

\begin{tabular}{|c|c|c|}
\hline No. & Stage & escription \\
\hline 1. & Idea & $\begin{array}{l}\text { All activities should address a socially important problem and have set objectives, for } \\
\text { which idea actions are taken, for example raising public awareness, changing the behaviour } \\
\text { of the local community. }\end{array}$ \\
\hline 2. & $\begin{array}{l}\text { Group of potential } \\
\text { allies / stakeholders }\end{array}$ & $\begin{array}{l}\text { The more partners/allies, the bigger the opportunities (public administration offices, market } \\
\text { entities whose subject matter is related to the campaign, well-known people, non-profit } \\
\text { organisations, media representatives, PR agencies, socially responsible commercial } \\
\text { companies, local community, volunteers). }\end{array}$ \\
\hline 3. & $\begin{array}{l}\text { Convincing partners } \\
\text { for cooperation }\end{array}$ & $\begin{array}{l}\text { In a specific problem situation, establishing cooperation with relevant stakeholders (for } \\
\text { example, at the local level - local media, companies operating in this market). }\end{array}$ \\
\hline 4. & Keynote & $\begin{array}{l}\text { Around what concepts are going to be presented, what is to be communicated (verbally and } \\
\text { graphically). }\end{array}$ \\
\hline 5 . & $\begin{array}{l}\text { Clarification of } \\
\text { campaign objective }\end{array}$ & Depending on the scale of the project, defining partial objectives. \\
\hline 6. & Facts & It is necessary to collect data, evidence and research that support the idea. \\
\hline 7. & $\begin{array}{l}\text { Development of the } \\
\text { activities range }\end{array}$ & $\begin{array}{l}\text { The selection of activities depends on the scale of the campaign and the addressees and } \\
\text { stakeholders attracted, the budget, the adopted communication strategy in accordance with } \\
\text { current trends (for example, in the implementation of campaign events, activities are } \\
\text { usually carried out on the Internet, but also picnics, rallies, meetings, events, leaflets and } \\
\text { information brochures, advertising boards, billboards, press, radio and other advertisements } \\
\text { depending on the means and inventiveness), in general, integrated promotional activities } \\
\text { are undertaken. }\end{array}$ \\
\hline 8. & $\begin{array}{l}\text { Implementation and } \\
\text { measurement of } \\
\text { results }\end{array}$ & $\begin{array}{l}\text { Timetable of implementation and methods of measuring results, checking if objectives have } \\
\text { been achieved. Plans for further actions, as social campaigns are often cyclical. }\end{array}$ \\
\hline
\end{tabular}

Source: M. Wojakowska, own elaboration based on: B. Tarczydło, Social campaign in theory and practice, AGH University of Science and Technology in Krakow. Use of new media in 
public relations / science editors. J.Gołuchowski, A. Frączkiewicz-Wronka. - Katowice: University of Economics Publishing House, cop. 2013. - p. 228 (access 30.08.2018)

The motivation to undertake social campaigns is mainly due to the need that is present in most of society, namely the need to do good, called the altruistic need to help. Promoters of non-commercial social campaigns are usually called "ideologists". However, apart from lofty motivations, it seems extremely important to have a methodical approach that ensures transparency of activities and organisational order in the very complex process that is the implementation of a social campaign.

Prochenko defines a social campaign as a "set of various planned activities at a specific time, directed to the specific target group, whose aim is to increase knowledge, change thinking, behaviour towards a specific social problem or solve a social problem blocking the achievement of the common good defined as a marketing goal".

Therefore, a good practice used by the research group under the ImProDiReT project was to organise a workshop meeting, during which mutual trust and openness were built through training of interpersonal skills.

A properly conducted social campaign uses various tools depending on needs and financial possibilities. However, it is important that the social campaign product is a change in social attitudes and an increase in the level of social awareness.

The egalitarian distribution of knowledge of a social and cultural nature through television, radio and press broadcasts favours the constitution of a new order and increases communication opportunities.

Social campaigns are to make people aware of the problem, pay attention to the size of the phenomenon, arouse interest in the problem and sense of danger (to make recipients aware that this phenomenon may also affect them), trigger specific feelings that trigger readiness to take action and initiate action. These objectives, in their practical layer, converge with the objectives of the commercial advertising model called AIDA:

- Attention

- I-interest

- D-desire

- A-action

Both commercial and social campaigns use the same techniques and means. The difference is therefore only a matter of presentation style.

"Attention" - first step. The ability to pay attention to the nature and scale of the problem among decision-makers and the general community.

A social campaign strives to evoke reflection, interest in difficult issues, often awareness, but also to shape specific, socially desirable patterns of human behaviour, change attitudes, and create social relations. However, the effectiveness of these messages is influenced by a whole range of factors, namely the awareness of the local authorities, the willingness to commit, and determination in finding the latest tools for communication with the public, but also involvement and public confidence in the authorities.

"Interest" - the second step. The art of arousing the interest of decision-makers. 
Preliminary interviews in the area of Solotvyno show that social campaigns are still a relatively new phenomenon. Therefore, the research team decided to develop a concept of a social campaign targeted at both the local community and local authorities/decision-makers.

"Desire" - the third step. The ability to convince decision-makers to be ready to implement the proposed concept of the campaign in cooperation with the public and partners and external stakeholders.

"Action" - the fourth step. It is possible for the sender of the campaign to reach the recipient directly and present added value from the implementation of the proposed preventive solutions.

The assumption of the Research Team is that the senders of the social campaign in question are all kinds of public, private, and governmental institutions, various associations, but also educational institutions, churches and religious organisations, and charitable foundations.

Also, active participation of local non-governmental organisations (NGOs) was established, which are voluntary organisations operating independently from state or political structures. NGOs work for social issues and the public good, and their work is largely based on the involvement of volunteers, which is why it is easier for them to reach the local community. This is mainly connected with the trust and respect that local leaders have towards the authorities, as a consequence creating local safety leaders among the community under study. Social campaigns addressed to "all people" are usually not very effective.

The research group decided to implement the public campaign in two groups of recipients. A group of teachers was chosen because adult teaching of children is very effective. Therefore, teacher training (showing practical educational methods) will help change the human mentality through children. The group of decision-makers is important because of the need to implement system solutions based on organisational and legal aspects that can be implemented in the realities of the Solotvyno region.

Therefore, the Research Team decided to prepare social campaigns addressed to the following groups:

- local authorities / decision-makers;

- children and youths adolescents;

- local social activists who, as "local authorities", will reach a wider community of local people.

\section{The Concept and Implementation of the Campaign Plan for Transcarpathia}

\subsection{Background - Transcarpathia (Area and Hazards)}

Transcarpathia (Закарпаття) is region in southwestern Ukraine, which borders upon four countries:

Poland, Slovakia, Hungary and Romania. Its administrative centre is the city of Uzhhorod. 


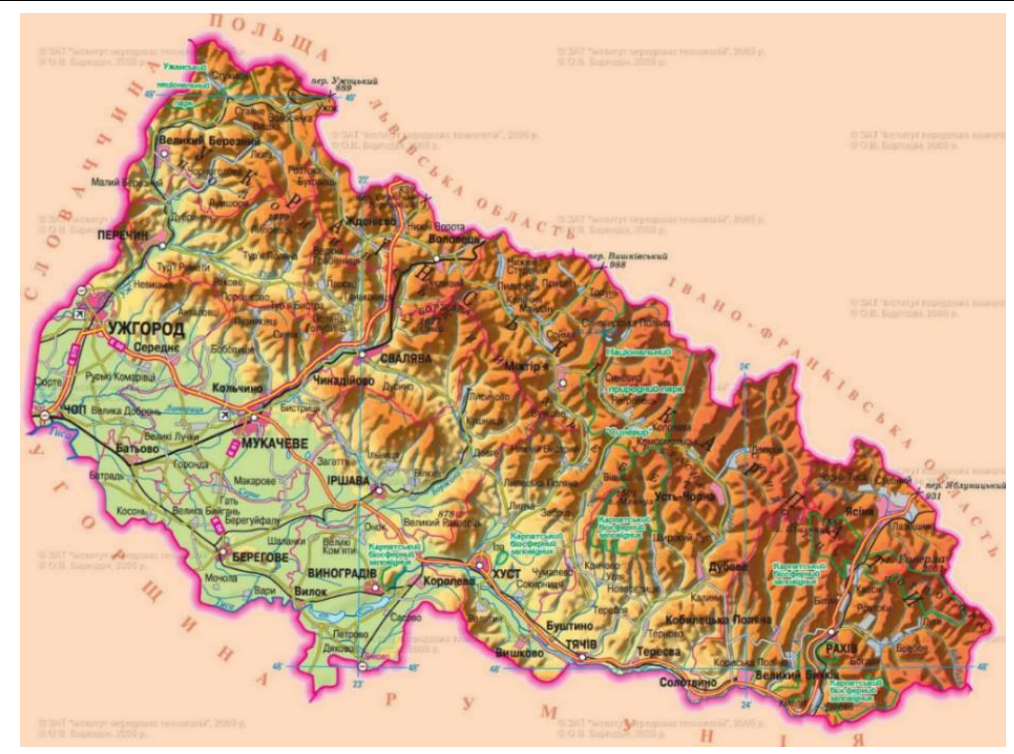

Figure 1. Map of The Transcarpathian region

Source: https://geomap.com.ua/ (access of the day 06.11.2019)

The region lies in an area where, for many years, salt mining and the consequences of mining activities have affected the people, the environment and the economy. These historically determined issues contribute (also indirectly) to the increase in the number of natural disasters, which is also closely related to regional hydrological, geological and hydrogeological conditions.

In order to reduce the risk of natural disasters in the Transcarpathian region, the assumptions of the ImProDiReT project were prepared and developed. It was assumed that the most effective form of introducing changes in this area is social dialogue implemented through social campaigns. Skillful social communication implemented as part of a social campaign begins the process of shaping a culture of safety in the Transcarpathian region. A complex approach to the social campaign will contribute to building cooperation between local decision-makers and society, which in turn will strengthen the sense of responsibility for jointly creating safety for their local communities.

A plan was prepared for a social campaign, in a rational way, that:

- enriches decision-makers' knowledge in the field of risk analysis methodology,

- indicates good practices in building social resilience through building social dialogue,

- raises public awareness of existing hazards,

- minimises the level of anxiety and powerlessness of residents by indicating specific countermeasures.

The scale of hazards and safety challenges that local decision-makers must face in Transcarpathia is very large and diverse. The risk of disasters and other local hazards is very 
high in the whole Transcarpathian region. The evidence-based approach is based on data collected as part of teamwork and numerous discussions with project partners.

The list of identified hazards in Transcarpathia includes, among others: landslides, heavy rains, drought (problem with drinking water), waste, etc.

The identified list of hazards cannot be just a set of data for use by local decision-makers. Information on the scale of hazards must be passed on to citizens.

The first step in the preparation of the social campaign was the visit of the research group to The Main School of the Fire Service (MSFS) in Solotvyno, in October 2018. A meeting with a group of local decision-makers was organised in order to get to know potential partners and to understand the problematic situation in the Transcarpathian region. The meeting took the form of workshops during which local decision-makers presented the main hazards and problems they face on a daily basis.

The main objective of the workshop was to show practical tools to help identify local hazards and consequences resulting from the lack of response to them. The methodology of risk analysis is presented, which is necessary when developing algorithms for minimising hazards. Attention was also paid to the need to develop skills to build a culture of trust, social involvement and cooperation between decision-makers and citizens. Only then can one talk about the effective development and implementation of system solutions.

The awareness campaign consists in preparing the next stages of activities. The first stage is defining the basic goals and assumptions of the campaign. Here, it is important to determine what we want to achieve, and what are our goals and assumptions.

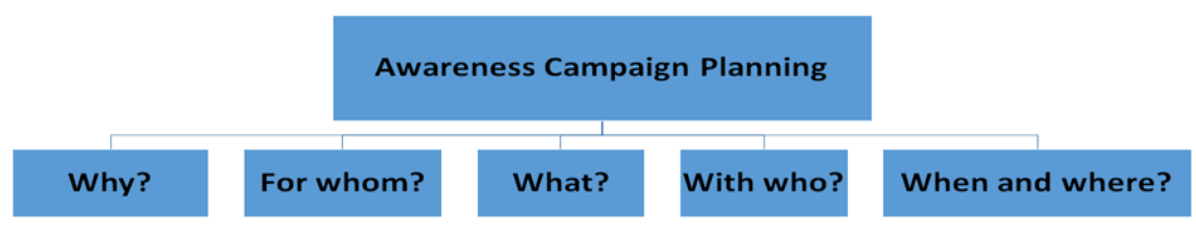

Figure 2. Social campaign planning procedure

Source: I. Grabowska-Lepczak, own elaboration

Why? Raising awareness and support in developing a comprehensive understanding of the population's environment.

For whom? Local and regional community: teachers, relevant stakeholders and decision-makers.

What? Workshops, publications, guide, leaflets, handbook - how to create an awareness campaign, bank of good practices - exchange of information, learning from others, use of other practices.

With whom? Cooperation and collaboration between ImProDiRet team, local and regional 
community.

When and where? Solotvyno, Uzhhorod, Transcarpathia, March 2019 - November 2019.

How? Among others, using the method "train the trainers", cooperating with local and regional leaders.

It is very important to determine which partners will help achieve the intended goals, the most obvious partners, but also potential partners. With partners in the first place, talks were held about expectations and joint cooperation. A good idea in implementing an effective and solid campaign is to use the "train the trainers" method. That is why workshops for teachers and representatives of NGOs and decision-makers have been prepared. An important element of the awareness campaign was the preparation of campaign products in four languages: Ukrainian, Romanian, Hungarian and English. Three of the languages were chosen because representatives of three ethnic groups: Ukrainians, Hungarians and Romanians, live in the Transcarpathian area; English because it is the language of the project. The prepared products are: a handbook, guide, brochures, leaflets and posters.

Bearing in mind that the awareness-raising campaign is an extremely important and valuable tool of social communication, promoting socially important ideas as well as appropriate, valuable behavioural patterns and attitudes, the research team decided to launch a comprehensive process of shaping a new safety culture in the region of Transcarpathia and Solotvyno.

The main areas in which our awareness campaign will be implemented are: local administration (local government) - regional decision-makers, ecology - environmental protection, education - children and youth through teachers and parents, and general safety education in safety for all.

The idea behind our activities is to create local safety leaders among a selected group of representatives of the local community. Bearing in mind that changes to long-established habits are extremely difficult, the implementation of changes was assumed through the education of children and youths.

For the needs of the implemented project, it was assumed that this social campaign will be informative and convincing.

The goal of the awareness campaign being carried out is to appeal to the emotions of the inhabitants, which is why we want to implement all the actions we undertake according to five simple rules:

- a simple and inspirational message,

- suggestive visual narrative - showing shocking contrasts, that are already evident, among others, in graphic terms on posters,

- displaying (posters, leaflets, brochures presented in both paper form and social media),

- various accents for various distribution channels, 
- appealing for help and social involvement (idea of local safety leaders).

The assumption of our activities is a comprehensive approach to the problem. We know that changing the mindset of the local community is not enough. Changes can be made, but local decision-makers must fully accept them. Therefore, an essential element of our campaign was to show the need to build mutual trust and commitment in citizen-power relations.

\subsection{Idea and Products of the Campaign}

Each hazard has its own importance and can affect people, the environment and/or infrastructure. Therefore, the campaign supports increasing public awareness of the hazards and highlights the significance of the phenomena. Landslides, especially in Solotvyno, are a serious problem that can materialise as a result of mining activity in the past. The occurrence of this hazard may have a significant impact on society by causing deaths and serious injuries, damage to buildings or local infrastructure (roads, electricity, etc.), or even disturbing natural processes. That is why more information about this hazard, its consequences and dedicated behaviour at different stages (before, during and after materialisation) is included in the "Handbook" and leaflets.
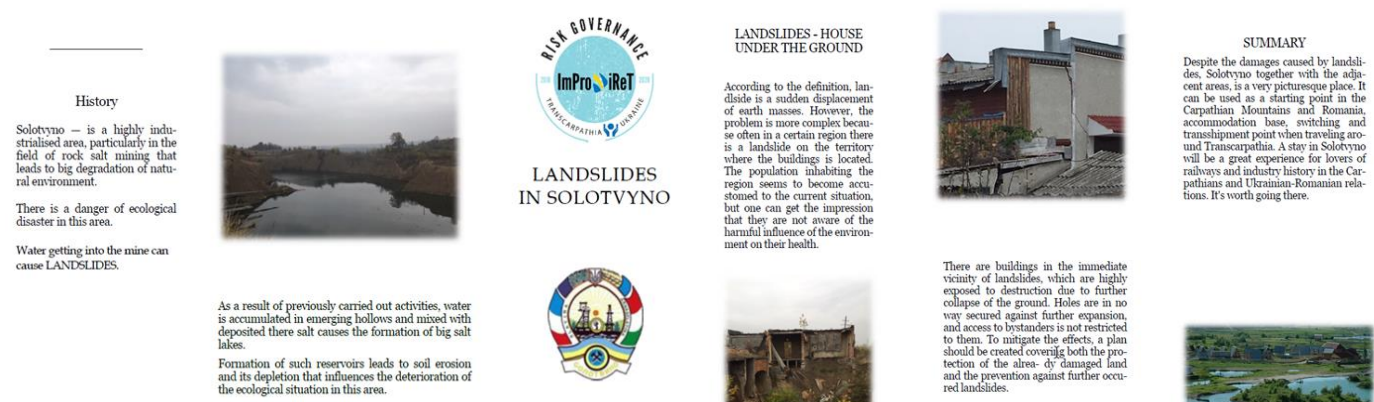

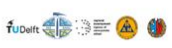
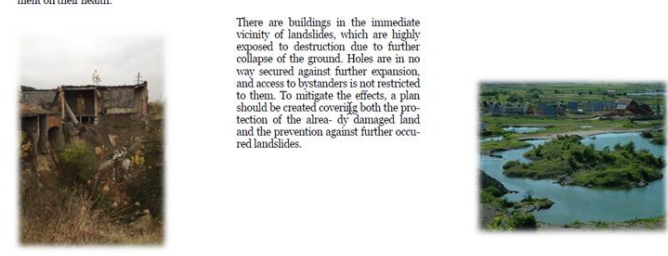

Figure 3. Example of leaflet presenting information about landslides

Source: researcher team of The Main School of Fire Service

A visit to the mining area and meeting with Solotvyno inhabitants and teachers showed the importance of the problem with waste and the necessity to include waste-related issues in the public awareness campaign. Moreover, unsuitable waste management or its lack may lead to or reinforce the occurrence of other hazards, for example increasing flooding and its consequences due to disturbances in the natural water flow caused by waste (including garbage) stored close to the rivers or in sinkholes; furthermore, it can influence the quality of soil, water, cultivation and air, or even contribute to fire. 

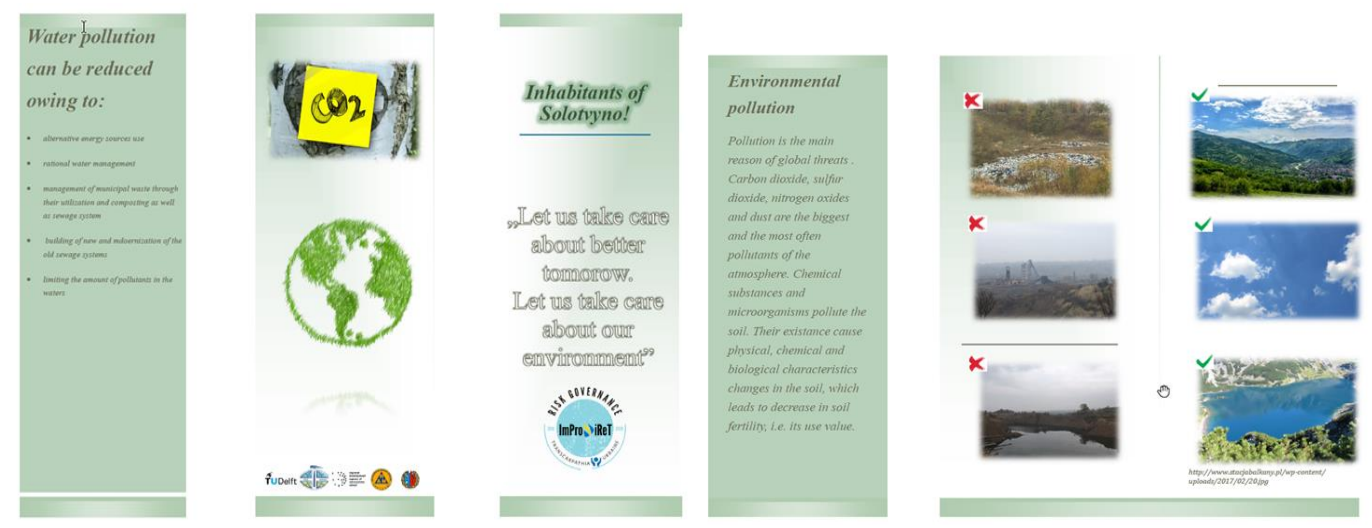

Figure 4. Example of leaflet presenting information about pollution

Source: researcher team of The Main School of Fire Service

Description of products prepared for the public awareness-raising campaign.

During the ImProDiRet project, the public awareness campaign was created with several specific products. Due to the fact that the population of Solotvyno and Transcarpathia is of different nationalities, all the products of the campaign were prepared in fourlanguages: English, Hungarian, Romanian and Ukrainian, to be understandable and approachable for every reader. All the products were developed by the ImProDiReT team from the Main School of the Fire Service.

The products are:

1. Guide "How to prepare an awareness campaign"

2. Handbook "Public awareness campaign"

3. Leaflets "Landslides in Solotvyno" and "Ukrainian Solotvyno at risk", "Water and environmental pollution"

4. Leaflet for the youngest "The little ecologist"

5. Poster "You can create your space"

Guide "How to prepare an awareness campaign" is a step-by-step guide directing an interested reader how to prepare the activity of an awareness campaign. It has been designed for the local community of Transcarpathia and Solotvyno. The guide includes the concept of the awareness campaign, stages of the effective social campaign, methods and ideas concerning finding different age audiences, and where to look for the campaign supporters.

A visit to the mining area and meeting with Solotvyno inhabitants and teachers showed the importance of the work is divided into 5 main parts:

1. What is an awareness campaign?

2. Research. 
3. Preparation.

4. Implementation.

5. Evaluation.

6. Next steps.

7. Step-by-step.

Handbook "Public awareness campaign", this focuses on issues related to the information campaign and threats in the Transcarpathian region. The main chapters present threats, a culture of trust, relationship building, an innovative concept shaping the safety of local communities - local leaders in safety and social communication, and a family emergency plan.

Leaflet "Landslides in Solotvyno" has been developed to persuade the recipient of the problems in the area. A hazard is presented concerning salt mining that leads to the degradation of the natural environment (soil erosion, landslides, ecological problems). The description is supported with pictures from the area. However, in the summary there is an optimistic point that the region is a picturesque place worth visiting because of its natural and historical background.

Leaflet "Ukrainian Solotvyno at risk" presents the geographical location of Solotvyno and its main problems, landslides, their causes, effects and ways of prevention. The leaflet is enriched with a map and pictures from Solotvyno.

Leaflet "Water and environmental pollution" shows the problem of environmental pollution, especially water pollution and the methods of reducing it. There are contrasting pictures showing negative situations, as for the pollution.

Poster "You can create your space" is a one-page poster prepared on the background of the picture from Solotvyno showing a salt mine. The slogan "You can create your space" inspires recipients to think about the future of the region and to search for solutions. Some of these are presented in the boxes on the poster: involvement, leadership, cooperation, assessment and implementation.

The next idea for the smart education was an activities workshop for teachers from the analysed region (on May 2019 in Warsaw) as part of the ImProDiReT project.

The aim of the workshop was, first of all, to create local leaders and provide tools to implement the campaigns in Uzhhorod and Solotvyno regions.

The most important issues that were worked on during the workshops were as follows:

- the aspect of local leadership and social communication, where a well-developed hazard identification is the first step in a long process of shaping the safety of the region;

- building involvement and a culture of trust; the process of social involvement should start with ourselves and small steps to "infect" others; the culture of trust is a great tool for building a bridge / agreement between a group of decision-makers and a group of active 
citizens.

During the workshops a lot of emphasis was put on the methodology of conducting information campaigns. After the theoretical introduction, participants were divided into three project groups, to prepare an information campaign plan for their regions in the context of specific local hazards.

During the presentation of the work results, everyone was impressed by the outcome. The participants' work proved that they had approached local problems with commitment and responsibility. During the classes, participants became familiar with the principles of the functioning of the mobile fire hazard simulator, and could learn about the effects of hazards designed in every room of a standard house in an innovative way.

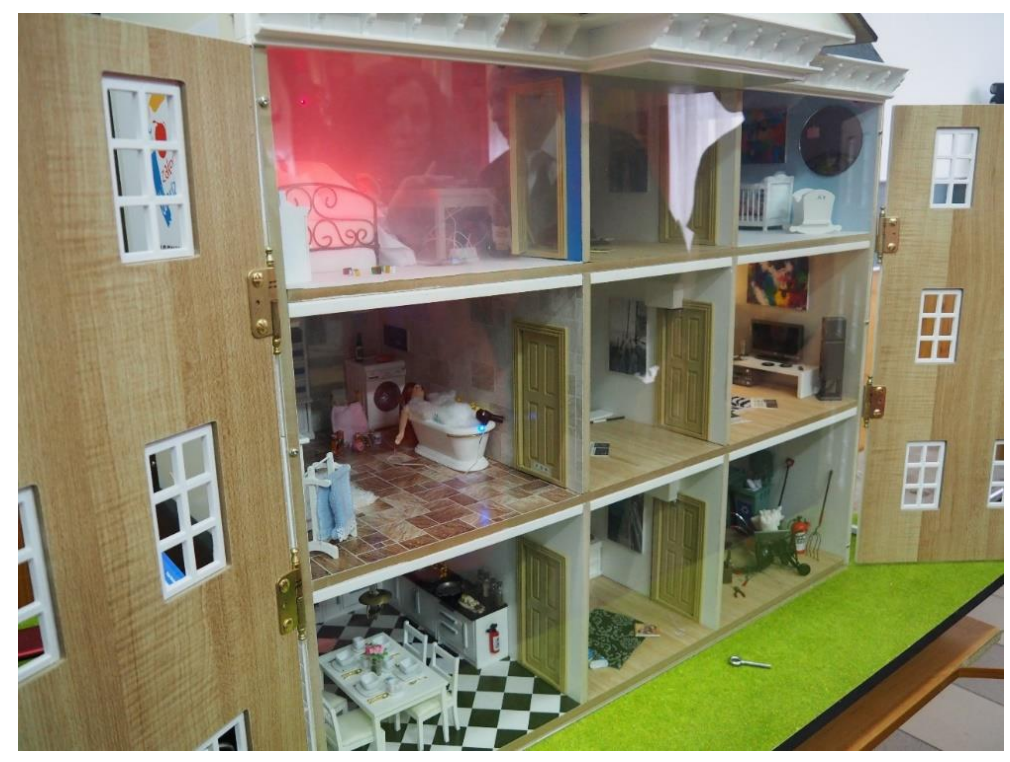

Figure 5. Mobile simulator of fire hazards. The rescue and fire-fighting unit No. 6 in Warsaw Source: I. Grabowska-Lepczak, own elaboration

As part of the workshops, the following social campaigns were developed for Transcarpathia:

1. Environmental pollution by domestic and industrial waste in the region.

Addressees: children, parents, students and teachers.

Goal: raising ecological awareness, encouraging ecological activities, directing recipients in relation to nature.

2. Ecological situation in Solotvyno and the global ecological situation in the Transcarpathian region.

Addressees: young people from the town of Solotvyno and tourists.

Objective: Safe life of our children and ourselves - a big problem: Solotvyno is like the dump of Ukraine. 
3. Island of safety

Addressees: Children, parents, teachers, local decision-makers, local institutions and the media

Objective: To raise children's knowledge about lurking dangers - reducing the number of accidents among children.

All groups showed a great sense of responsibility, decisiveness and determination, as well as openness and a constructive spirit and a will to overcome the potential difficulties.

The conclusion of the workshop allows us to state that the goal of the workshop has been achieved and we only have to wait for the results of the implemented ideas and the results of changes in individual local communities.

At the end of the workshop, an evaluation survey was carried out. The results were very positive, and the participants rated both the substantive and organisational aspects very well. They pointed to the need to organise more such activities.

Everyone agreed that the issues presented during the workshop helped to deepen the knowledge about safety, building relationships and creating awareness campaigns. They received a lot of theoretical material and a lot of practical information. The materials received during the workshops were very helpful and at a high level and useful.

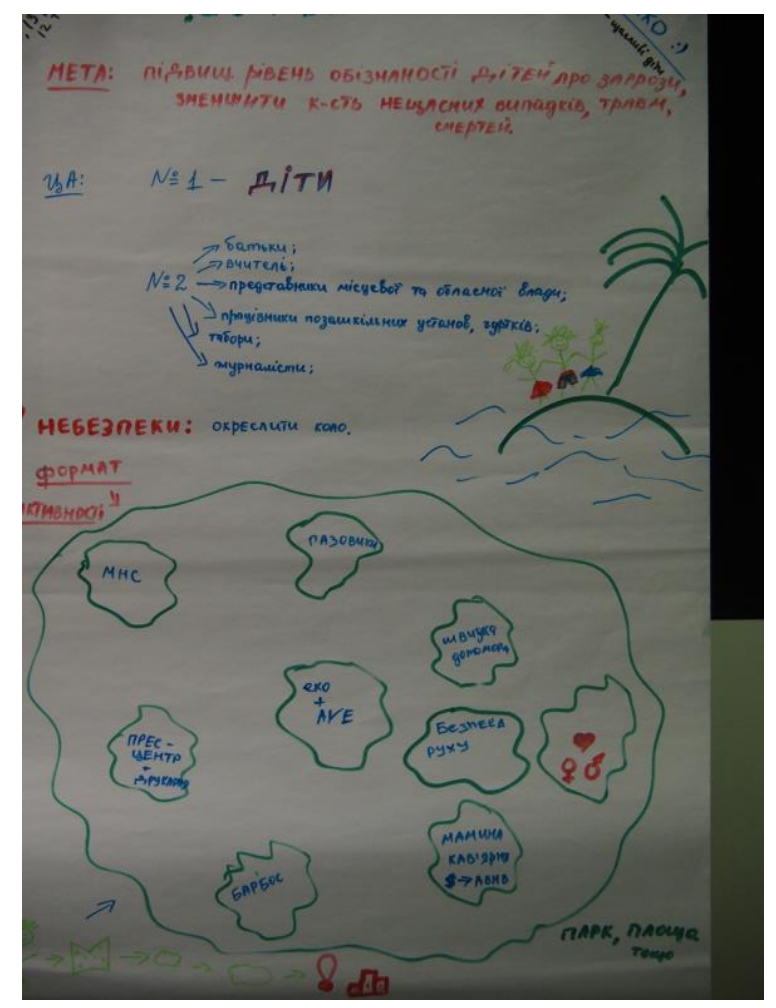

Figure 6. An example of Awareness Campaign designed by workshop participants

Fot: I. Grabowska-Lepczak, 
All participants were satisfied with the participation in the workshop. The issues on which the workshops should be extended include primarily:

- the participation of local authorities,

- work experience,

- other types of hazards - how to behave.

Development education and raising the awareness of inhabitants should be considered a priority. To make that happen, the intention is that all necessary forces should join together to support Transcarpathian region.

The team at The Main School of the Fire Service responsible for the awareness campaign gave priority to local decision-makers in creating a culture of trust and building involvement in the shared future of the region.

Workshop meetings for decision-makers were held in September 2019 in Uzhhorod. For two days the following areas were raised: risk analysis, communication, relationship building, involvement and social prevention. The goal was to convince decision-makers to initiate social campaigns to raise public awareness, and that local safety leaders should support local decision-makers in communicating this message to citizens.

Society should be aware of hazards, but must not be overwhelmed by their scale and extent. That is why we want to support the development of a culture of safety. Particular attention was paid to the need to develop the skills to build a culture of trust, social commitment and cooperation between decision-makers and citizens. The need for dialogue with society was pointed out, creating the idea of "local safety leaders", because the role of decision-makers is to identify local social activists who have authority among local communities. The next objective of the workshop was to show the methodology of risk analysis, which is necessary when developing algorithms for minimising hazards.

In our opinion, the values that are relevant to engagement are as follows:

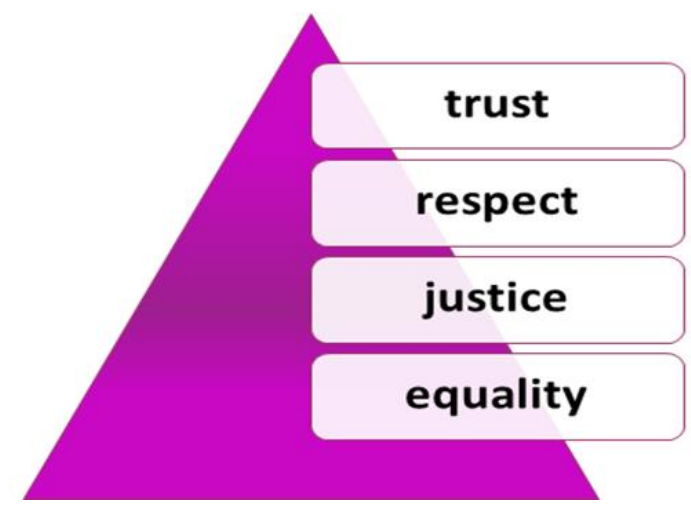

Figure 7. The values that are relevant for involvement

Source: B. Szykuła-Piec, own elaboration 
The important part of the workshop concerned trust, and normative stability understood as a transparent and logical system of rules (legal, moral and customary rules), guaranteeing responsibility for a sense of order, predictability and objective safety. In addition, attention was paid to the transparency of the social organisation:

- clear rules of operation,

- visible results of these principles,

- structure control and activities.

The presence of authorities whose task is to protect threatened privileges, but also to ensure that the obligations assigned to the relevant entities are met, is also important.

With this in mind, the goal was to increase confidence in local authorities and create a friendly and safe environment for the population. Our workshops showed how decision-makers can engage in dialogue with the public, creating the idea of "local safety leaders".

\section{Conclusion}

The conclusions indicate that there is no one formula that can guarantee that the awareness campaign will always be effective, but it is influenced by basic principles: the choice of the method of creating local leaders (e.g. decision-makers, teachers), the devising of a campaign slogan that would easily catch the imagination, of a media-friendly nature, the engagement of the recipients in undertaking activities on their own, but giving direction in an oriented way for elaborating on possible scenarios to determine that each of us has an impact on our surroundings and the environment in which we live.

There is no doubt that the education of society regarding safety is in fact the cheapest, smartest and most effective way of preventing danger. It is a good way to turn knowledge into activities. To build desirable attitudes, values and skills required for proper behaviour in the case of danger is the priority. The given example of a practical approach to smart education for all stakeholders, to raise the level of social awareness in Transcarpathia to threats occurring in the area and ways to counteract them, forms a very important part of the strategy of global safety.

\section{Others}

Department of Education Science and Training, 2005. Research Quality Framework: Assessing the Quality and Impact of Research in Australia. Canberra, Australia: Commonwealth of Australia.

EU follow up and advisory mission to support the Government of Ukraine in the field of Civil Protection FINAL REPORT, Union Civil Protection Mechanism; April 2016, Advisory Mission to Ukraine: Solotvyno salt mine area. Executive Summary of the RISK ASSESSMENT REPORT, Union Civil Protection Mechanism, October 2016. 
List of Hazards - Transcarpathia and List of Hazards Solotvyno, Report D1.1; D1.2 Improving disaster risk reduction in Transcarpathian region, Ukraine; Union Civil Protection Mechanism, February 2019.

http://www.kampaniespoleczne.pl/publikacja (accessed 02/06/2012).

\section{Glossary}

AIDA: A-attention, I-interest, D-desire, A-action

FGI: The focus group interview

ImProDiReT: Improving disaster risk reduction in Transcarpathian region

MSFS: The Main School of the Fire Service

NGOs : Non-governmental organisations

PR: Public relation

UN: United Nations

UNESCO: United Nations Educational, Scientific and Cultural Organization

\section{Acknowledgement}

This work was supported by project Improving disaster risk reduction in Transcarpathian region, Ukraine; Union Civil Protection Mechanism, Grant Agreement number: 783232 ImProDiReT — UCPM-2017-PP-AG, DG ECHO Programme.

\section{References}

Bornmann, L. (2012). Measuring the societal impact of research. Research is less and less assessed on scientific impact alone-we should aim to quantify the increasingly important contributions of science to society. Science \& Society, 13(8). https://doi.org/10.1038/embor.2012.99

Bornmann, L. (2013). What is societal impact of research and how can it be assessed? A literature survey. Journal of the American Society for Information Science and Technology, 64(2). https://doi.org/10.1002/asi.22803

Bourdieu, J. C. (1979). The inheritors. University of Chicago Press.

Coleman, J. S. (1990). Foundations of social theory. Harvard University Press, Cambridge MA.

Dobek-Ostrowska, B. (2007). Komunikowanie polityczne i publiczne. PWN, Warsaw.

Donovan, C. (2008). The Australian Research Quality Framework: A live experiment in capturing the social, economic, environmental, and cultural returns of publicly funded research. New Directions for Evaluation, 118. https://doi.org/10.1002/ev.260

Hollnagel, E. (2015). Introduction to the Resilience Analysis Grid (RAG): RAG-Resilience Analysis Grid. 
Kwiatkowska, M. (2003). Obraz świata $w$ reklamie społecznej. II Międzynarodowy Festiwal Fotografii, Lodz.

Maison, D., \& Wasilewski, P. (2002). Propaganda Dobrych Serc, czyli pierwszy tom o Reklamie Społecznej (2nd ed.). Agencja Wasilewski, Cracow.

Mulder, P. (2012), Walt Disney Method. Retrieved from https://www.toolshero.com/creativity/walt-disney-method/

Putnam, R. D. (2008). Samotna gra w kręgle. Upadek i odrodzenie wspólnot lokalnych w Stanach Zjednoczonych. Warsaw.

Ragin, Ch. C., \& Amoroso, L. M. (1994). The Goals of Social Research. In: Constructing Social Research: The Unity and Diversity of Method, Northwestern University, Pine Forge, Thousand Oaks.

Salter, A. J., \& Martin, B. R. (2001). The economic benefits of publicly funded basic research: A critical review. Res Policy, 30. https://doi.org/10.1016/S0048-7333(00)00091-3

Szykuła-Piec, B. (2018). Propozycja zastosowania wybranych elementów teorii wymiany w celu identyfikacji procesów integracji społecznej $w$ kontekście ksztaltowania bezpieczeństwa. Zeszyty Naukowe SGSP, Nr 68/4, Warsaw.

van der Meulen, B., \& Rip, A. (2000). Evaluation of societal quality of public sector research in the Netherlands. Res. Eval., 9. https://doi.org/10.3152/147154400781777449

van Vught, F., \& Ziegele, F. (Eds.) (2011). Design and testing the feasibility of a multidimensional global university ranking. Final Report. European Community, Europe: Consortium for Higher Education and Research Performance Assessment, CHERPA-Network.

\section{Copyright Disclaimer}

Copyright reserved by the author(s).

This article is an open-access article distributed under the terms and conditions of the Creative Commons Attribution license (http://creativecommons.org/licenses/by/3.0/). 